\title{
Opinions of the Physical Education Teachers about the Effect of Peer Education and Physical Activity Cards' Usage on the Student Skills
}

\author{
Mustafa Karadağ $\breve{1}^{1}$ Yüksel Savucu ${ }^{1}$, Resul Ağırtaş ${ }^{2} \&$ Gülbin Eskiyecek ${ }^{3}$ \\ ${ }^{1}$ Faculty of Sports Science, Firat University, Elazığ, Turkey \\ ${ }^{2}$ Physical Education and Sport Teacher, National Education Ministry, Elazı̆̆ , Turkey \\ ${ }^{3}$ School of Physical Education and Sport, Artuklu University, Mardin, Turkey \\ Correspondence: Mustafa Karadağ, Faculty of Sports Science, Firat University, Elazı̆̆g, Turkey. E-mail: \\ kent00023@hotmail.com
}

Received: May 22, 2018

Accepted: October 27, 2018 Online Published: December 31, 2018

doi:10.5539/jel.v8n1p172

URL: https://doi.org/10.5539/jel.v8n1p172

\begin{abstract}
The purpose of this study was to determine the opinions of the physical education teachers about the effect of peer education and physical activity cards' usage on the student skills. Physical education teachers used a questionnaire to follow the students through observation. One-hundred-twenty secondary school students in 2015-2016 semester in Elazığ participated to the study. The students in the sample group were divided into two 30-person groups and control group and experimental group were constituted. The formed groups were taught lessons by means of Physicak Activity Cards for 4 weeks. At the end of the four-week course period, opinions about peer education were obtained through individual and focus group interviews with the experimental and control group students. In addition, "Skill Learning Observation Forms" prepared by researchers and experts were also applied. In the analysis of the data, for qualitative dimension, descriptive analysis, for quantitative data, percentage, frequency, for repetitive measurements, $t$ test and one-way variance analysis were used. The SPSS 22 package program was used for the analysis of the quantitative data. The quantitative data were explained through tabulation. Again, the data obtained from observation forms were presented in the form of tables with their frequency and percentage values. Themes were obtained by coding the qualitative data. When the influence of the physical activity cards on the students' attitudes toward the class is considered, a significant difference was attained in the common effect of the experimental group. According to this result, the education received by the students in the experimental and control groups led to a significant difference in favor of the last-test at the preand post-program attitude levels. However, it was determined that being in different groups did not lead to a significant difference in students' attitude scores. When we examined the student opinions about the cards, the most of the students expressed the opinions that teaching lessons through cards created difference in the classes and increased their participation in the class. It was also enhanced their exercise skills and self-confidence. They did not have difficulty while applying the cards, they led them to act in coordination, and they rendered the class more enjoyable.
\end{abstract}

Keywords: education, physical activity card, physical education and sports, teacher

\section{Introduction}

In our country, when Physical Education and Sports course curriculum at primary school, $5-8^{\text {th }}$ grade, is examined, it is seen that it recommends that the Physical Activity Cards (PAC) are used as the teacher's lecturing technique. When the literature is examined, it is seen that it first time was used in the UK under the name of TOPs Cards.

This method was discovered by the teachers working in the institution named "Young and Sport Trust" established in England in 1994 with the aim to develop the movements included in physical education and sports programs, to improve the quality of the program and to make the subjects in the program applicable. This method consists of two programs, Top Play and Top Sport. Top Play focuses on teaching basic motor skills to the children at first childhood period (4-7 years). Top Sport method aims to develop the potential of the individuals who are in the secondary childhood period (7-11 years), and to gain them new skills. These methods were incorporated into primary school curriculum in England between the years of 1996-1997. In 2002, they were 
again revised for Physical Education and Sports national curriculum and a new page was opened for these programs. The objectives of these methods are to expand the content of the physical education and sports programs, to increase the effectiveness of the program, to make individuals repeat to learn, to increase knowledge and skill levels and self-confidence of the teachers who are the implementers of the program, and to give students the joy of the course of physical education and sports and to increase it (http:// www.uluslararasiilham.org.tr).

Top Play and Top Sport methods are the cards that will help candidate teachers, incumbent teachers, sports coaches, and instructors who work in institutions and organizations where sportive activities are carried out, and that are produced to improve the quality of physical education and sports activities. Seminars and courses for teachers were organized about the implementation of this method and a professional TOPs development program was created. In Turkey as well, this method was included in the Physical Education Curriculum prepared by Ministry of Education, Board of Education, taking example from the International Inspiration Project; and PAC were developed for the use of classroom teachers, physical education teachers, sports coaches and sports trainers (http: //www.uluslararasiilham.org.tr).

Many studies on PAC have been conducted and articles elaborating on this method were published. Sabin (1997) provided information about the implementation of TOPs cards in his study he published in 1997; Roberts et al. (1998) examined Top Play and Top Sport models in the North West and made a statement and determined positive and negative aspects of this method. According to this study; the following may be cited as the positive aspects of the TOPs methods, although weight is given to literature and mathematics courses in the education-training process: TOPs method can be applied in physical education and sports courses; with the purpose of implementing this method, knowledge and skills of the relevant teachers are increased through in-service training or professional development courses. The disadvantages of the method are cited as: specified time periods are determined for transferring the implementation of the method to the teachers, lack of sufficient resources to implement the method, the difficulties in establishing the systems required by the method in school environments, and long-term traces that this system leaves on schools.

Harris, Cale \& Musson (2007), in their report about the results of the implementation of TOPs methods in the schools, showed that this method provides realization of the following objectives: to help the physical education teachers; to enhance their professional development; to gain teachers, who do not have sufficient knowledge and skills in their respective fields, competence and to enhance their knowledge and skills; to raise awareness of students about physical education program; to increase the number of scientific studies about the implementation of TOPs methods in schools; to increase the efficiency of physical education and sports courses in schools; to reveal by means of researches the problems experienced in the implementation of TOPs methods in schools and to develop solutions; to increase the self-confidence of teachers by increasing their knowledge and skills levels; to give a more prominent position to the physical education and sports courses within the education system; to ensure participation of the students in sports activities during physical education classes; and to hold events that will arouse the desire of individuals to perform sports activities.

TOPs cards were created at the "International Inspiration" program, which was organized within the scope of the Olympic Games held in London in 2012, with the purpose of making physical education and sports a part of lives of the individuals and spreading the program, which was implemented in 5 countries, to 20 countries and making it reach to 12 million children (http://www.uluslararasiliham.org.tr).

The International Inspiration program was developed through supports of the British Council, UK Sports Authority, UNICEF, UK Ministry of International Development, UK Ministry of Foreign Affairs, British Olympic Foundation and London Olympic Games Organizing Committee, and incorporated into the education curriculum as TOPs abroad and as PAC in our country. In Turkey, this method is supported by Turkish National Olympic Committee, Ministry of Youth and Sports, Ministry of Family and Social Policies, Turkish National Paralympic Committee and Ministry of Education.

PAC were introduced into the curriculum of primary education of our country in the year of 2012 with a view to gaining the students basic motor skills, teaching some special sports movements, and actively using the constructive approach in the education process. With PAC it was aimed to increase students' participation in sports activities and games played in this scope in the schools and thus to strengthen their bond with the school, and to increase the efficiency in the educational process through their playing games appropriate to their age, gender and physical structure (National Education Ministry, 2012).

PAC, too, consist of two parts, as in TOPs cards. In the first part, there are PAC that will teach and develop the gains specified in the Game and Physical Activity Course Curriculum (1-4 grade), and that are appropriate to the 
children's physical characteristics in their developmental periods in the first childhood period (6-9 years of ages). In addition, in the second part of the PAC there are cards towards developing basic skills that the students, who are in secondary childhood period (10-13 years of ages), are required to have in leading them to the sports branches that are suitable for their physical structure and area of interest (http://www.uluslararasiilham.org.tr).

In the method of PAC applied in our country, cards are composed of two groups, yellow cards and purple cards. In the yellow cards group related to the first childhood period (6-9 years of ages) there are 34 kinds of cards such as basic movement skills and concepts cards, teacher cards, combined movements cards, health understanding cards, sports cannot be stopped cards, movement competency cards, and physical activity and nutrition pyramid cards. And within the purple cards group related to the secondary childhood period (10-13 years of ages) there are 49 kinds of cards such as "teacher cards, net and racket games, attack games, hitting and catching games, active participation, health understanding, and sports cannot be stopped cards (National Education Ministry, 2012).

While the front sides of both yellow and purple PAC contain information such as short descriptions of games and movements, drawings of games and movements, materials to be used, and safety precautions, their back sides contain the "Learning Key", which should be considered in order to learn the games or movements given on the front side, "Assessment and Improvement" that include flexibilities (facilitating or making difficult the movements) that can be applied during events, and "Health Understanding" (57). Now let's examine one sample from yellow and purple cards each:

In the teacher cards, included among the PAC, there is information about the use of cards by teachers as well as explanations on the points to be considered in using the PAC. If the PAC will be used for the gain, which is included in the education program, in a particular order, the order according to which they are to be used is indicated. In addition to forming the basis of the program, the cards also contain explanations on students' current skills, or on new movements, games, demonstrations, dance figures, and gains and movements indicated in the program, which they will learn. While yellow-orange card groups from among the PAC groups contain the activities appropriate to the age and physical development characteristics of 1-3 grade students, it is recommended to select appropriate activities in the yellow or purple card groups, which will be suitable for to the age and physical development characteristics of $4^{\text {th }}$ grade students. The appropriate card group should be selected according to the different development levels and age groups of the students and implemented. The activities in purple card groups are generally more suitable for the physical development characteristics of 4-8 grade students. (National Education Ministry, 2012).

The characteristics of the PAC are as follows (Torphe, 2013): S (Success), M (Maximum Participation), I (Inclusive), L (Learning), E (Enjoyment), S (Socialization).

The objective of this study is to examine the effects of the PAC on the attitudes of secondary school students towards the course of physical education and sports.

\section{Methodology}

The skill rating scale that was developed with the researcher and 3 instructors and the skill rating scale prepared with the expressions contained in the learning key section of the Purple Cards included in the PAC implemented in the Physical Education and Sports Course were applied (Annex-4). The construct validity of the Skill Assessment Scale was calculated and the Cronbach alpha value was calculated as .849 and KMO Kaiser-Meyer-Olkin Measure of Sampling Adequacy value was calculated as .742. These results indicate that the construct validity of the scale is at adequate level.

\subsection{Analysis of Qualitative Data}

In the research, the "descriptive analysis" method from among the qualitative analysis methods was used in order to analyze the data in an understandable way, to examine cause and effect relations and to reach some results, and to interpret the findings. The diaries kept by two teachers were tabulated in the computer media by the researcher. Then, the common points in the data were rendered short sentences and coded. The codes were grouped into themes, overlapping with each other, by the researcher and an academician who is expert in the qualitative research methods.

\subsection{Analysis of Quantitative Data}

Two-factor variance analysis (Duration: pretest - posttest / Group: experimental / control) was used for repetitive measurements. The level of significance in the study was taken as 0.05 . To the opinions obtained from the students, $\%$ and frequency, from among the descriptive statistical techniques, were applied. 


\section{Results}

According to the results obtained in this study, two physical education teachers stated, with respect to the physical education cards and peer education that were applied to $7^{\text {th }}$ grades, that the method was appropriate, but the teacher guidance was needed and classroom control was generally ensured in all classrooms during the application. The teachers pointed out that however, in some cases, teacher guidance was needed and the vast majority of the students participated in the application. In addition, the teachers unanimously thought that now new projects and methods should be tested in our education system instead of the classical methods and we should go beyond the monotony. According to the opinions of the Physical Education and Sports teachers who applied the PAC in their classes, the PAC ensure success, self-management and socialization in students, increase participation in class, improve communication skills, and they found them to be funny and instructive.

Table 1. General opinions of the teachers on the "skill rating scale" for the Experimental Group students-(p $<0.05$

\begin{tabular}{|c|c|c|c|c|c|c|c|c|c|}
\hline \multirow{2}{*}{ M } & \multirow{2}{*}{ Skill rating scale } & \multirow{2}{*}{$\mathrm{N}$} & \multicolumn{5}{|c|}{ Agreement Level (\%) } & \multirow{2}{*}{$\bar{X}$} & \multirow{2}{*}{ ss } \\
\hline & & & weak & medium & good & well & Perf. & & \\
\hline 1 & Head is up for controlling other players and the area. & 60 & 0 & 0 & 0 & 20.0 & 80.0 & 4.80 & 0.40 \\
\hline 2 & $\begin{array}{l}\text { The transportation method (rolling, driving, passing, } \\
\text { etc.) appropriate to the selected material is used. }\end{array}$ & 60 & 0 & 0 & 0 & 50.0 & 50.0 & 4.50 & 0.50 \\
\hline 3 & $\begin{array}{l}\text { The ball is checked close to the body while going } \\
\text { through the passageways. }\end{array}$ & 60 & 0 & 0 & 3.3 & 51.7 & 45.0 & 4.41 & 0.56 \\
\hline 4 & $\begin{array}{l}\text { While moving with the ball, moves forward seeing both } \\
\text { the ball and the obstacle. }\end{array}$ & 60 & 0 & 0 & 3.3 & 55.0 & 41.7 & 4.38 & 0.55 \\
\hline 5 & Is prepared for sudden stops and direction changes. & 60 & 0 & 0 & 10.0 & 41.7 & 48.3 & 4.38 & 0.66 \\
\hline 6 & $\begin{array}{l}\text { Makes eye contact with the corresponding player when } \\
\text { giving and receiving pass. }\end{array}$ & 60 & 0 & 0 & 8.3 & 40.0 & 51.7 & 4.43 & 0.64 \\
\hline 7 & $\begin{array}{l}\text { Shows his readiness, with his body position, for taking } \\
\text { the ball. }\end{array}$ & 60 & 0 & 0 & 3.3 & 36.7 & 60.0 & 4.56 & 0.56 \\
\hline 8 & Follows the ball well. & 60 & 0 & 0 & 3.3 & 38.3 & 58.3 & 4.55 & 0.56 \\
\hline 9 & Takes appropriate shooting and capturing positions. & 60 & 0 & 0 & 6.7 & 28.3 & 65.0 & 4.58 & 0.61 \\
\hline 10 & $\begin{array}{l}\text { Gives the pass in a way that the corresponding player } \\
\text { can take it. }\end{array}$ & 60 & 0 & 0 & 1.7 & 40.7 & 57.6 & 4.55 & 0.53 \\
\hline 11 & $\begin{array}{l}\text { Shows a target by hand to indicate readiness to catch the } \\
\text { ball. }\end{array}$ & 60 & 0 & 0 & 5.0 & 35.0 & 60.0 & 4.55 & 0.59 \\
\hline 12 & Throws the ball at the specified target. & 60 & 0 & 0 & 5.0 & 48.3 & 46.7 & 4.41 & 0.59 \\
\hline 13 & Sends the ball to the desired point at an adequate speed. & 60 & 0 & 0 & 3.3 & 45.0 & 51.7 & 4.48 & 0.56 \\
\hline 14 & Follows the thrown ball by his eye. & 60 & 0 & 0 & 1.7 & 45.0 & 53.3 & 4.51 & 0.53 \\
\hline 15 & $\begin{array}{l}\text { Moves quickly to go away from the defense players and } \\
\text { is ready to pass. }\end{array}$ & 60 & 0 & 0 & 8.3 & 50.0 & 41.7 & 4.33 & 0.62 \\
\hline 16 & $\begin{array}{l}\text { The offensive players take the position of the defensive } \\
\text { players into account while passing. }\end{array}$ & 60 & 0 & 0 & 3.3 & 53.3 & 43.3 & 4.40 & 0.55 \\
\hline 17 & Makes different shots / throws at the target. & 60 & 0 & 0 & 5.0 & 58.3 & 36.7 & 4.31 & 0.56 \\
\hline 18 & $\begin{array}{l}\text { Ebes passes at appropriate speed, taking into account } \\
\text { the distance. }\end{array}$ & 60 & 0 & 0 & 6.7 & 58.3 & 35.0 & 4.28 & 0.58 \\
\hline 19 & When ready to catch pass, shows by targeting his hand. & 60 & 0 & 0 & 8.3 & 50.0 & 41.7 & 4.33 & 0.62 \\
\hline 20 & $\begin{array}{l}\text { After pass is made, immediately takes the pass-taking } \\
\text { position. }\end{array}$ & 60 & 0 & 0 & 8.3 & 48.3 & 43.3 & 4.35 & 0.63 \\
\hline 21 & The offensive player shows his readiness to take pass. & 60 & 0 & 0 & 1.7 & 50.0 & 48.3 & 4.46 & 0.53 \\
\hline 22 & The offensive players go to empty spaces to get passes. & 60 & 0 & 0 & 1.7 & 48.3 & 50.0 & 4.48 & 0.53 \\
\hline 23 & $\begin{array}{l}\text { The player kicks the ball towards cruciate to gain space } \\
\text { and run inside to get the ball. }\end{array}$ & 60 & 0 & 0 & 16.7 & 60.0 & 23.3 & 4.06 & 0.63 \\
\hline 24 & $\begin{array}{l}\text { When making defense, first uses backward, leftward } \\
\text { and rightward side steps. }\end{array}$ & 60 & 0 & 0 & 43.3 & 40.0 & 16.7 & 3.73 & 0.73 \\
\hline 25 & Defense players give a clear signal to get the ball. & 60 & 0 & 0 & 26.7 & 51.7 & 21.7 & 3.95 & 0.69 \\
\hline 26 & Passes to the free player. & 60 & 0 & 0 & 15.0 & 53.3 & 31.7 & 4.16 & 0.66 \\
\hline 27 & Uses side steps to mislead the defender. & 60 & 0 & 0 & 1.7 & 56.7 & 41.7 & 4.40 & 0.52 \\
\hline 28 & Tries to make accurate passes. & 60 & 0 & 0 & 30.0 & 43.3 & 26.7 & 3.96 & 0.75 \\
\hline 29 & Passes in different directions. & 60 & 0 & 0 & 6.7 & 46.7 & 46.7 & 4.40 & 0.61 \\
\hline 30 & Changes the direction of the game by a single pass. & 60 & 0 & 0 & 5.0 & 43.3 & 51.7 & 4.46 & 0.59 \\
\hline
\end{tabular}




\begin{tabular}{|c|c|c|c|c|c|c|c|c|c|}
\hline 31 & Moves to empty spaces to get pass. & 60 & 0 & 0 & 1.7 & 51.6 & 46.7 & 4.45 & 0.53 \\
\hline 32 & Runs fast at wings to get pass. & 60 & 0 & 0 & 5.0 & 41.7 & 53.3 & 4.48 & 0.59 \\
\hline 33 & Uses side steps to get pass in the wings. & 60 & 0 & 0 & 5.0 & 48.3 & 46.7 & 4.41 & 0.59 \\
\hline 34 & Uses side steps to get pass in the wings. & 60 & 0 & 0 & 15.0 & 51.7 & 33.3 & 4.18 & 0.67 \\
\hline 35 & Cheats to get pass in the wings. & 60 & 0 & 0 & 8.3 & 50.0 & 41.7 & 4.33 & 0.62 \\
\hline 36 & $\begin{array}{l}\text { The player in the wings gives the pass to the most } \\
\text { suitable player for the offense. }\end{array}$ & 60 & 0 & 0 & 5.0 & 46.7 & 48.3 & 4.43 & 0.59 \\
\hline 37 & Controls the player on the wing while defending. & 60 & 0 & 0 & 5.0 & 53.3 & 41.7 & 4.36 & 0.58 \\
\hline 38 & $\begin{array}{l}\text { Works in coordination while making offense and } \\
\text { defense. }\end{array}$ & 60 & 0 & 0 & 3.3 & 46.7 & 50.0 & 4.46 & 0.56 \\
\hline 39 & $\begin{array}{l}\text { Communicates with teammates while making offense } \\
\text { and defense. }\end{array}$ & 60 & 0 & 0 & 1.7 & 38.3 & 60.0 & 4.58 & 0.53 \\
\hline 40 & Moves forward in empty space to get pass. & 60 & 0 & 0 & 3.3 & 43.3 & 53.3 & 4.50 & 0.56 \\
\hline 41 & Tries to make and catch appropriate pass. & 60 & 0 & 0 & 1.7 & 53.3 & 45.0 & 4.43 & 0.53 \\
\hline 42 & Adjusts pass distance and speed well. & 60 & 0 & 0 & 1.7 & 51.7 & 46.7 & 4.45 & 0.53 \\
\hline 43 & Trains at proper speed until skill develops. & 60 & 0 & 0 & 1.7 & 64.4 & 33.9 & 4.32 & 0.50 \\
\hline 44 & $\begin{array}{l}\text { When starting learning the movement, makes passes } \\
\text { and shots by sitting or standing still. }\end{array}$ & 60 & 0 & 0 & 6.7 & 56.7 & 36.7 & 4.30 & 0.59 \\
\hline 45 & $\begin{array}{l}\text { Tries different ways of controlling the ball (by hand, } \\
\text { with crutches, wheelchair, etc.). }\end{array}$ & 60 & 0 & 0 & 13.3 & 55.0 & 31.7 & 4.18 & 0.65 \\
\hline 46 & Dedicates enough time to develop the skill. & 60 & 0 & 0 & 8.3 & 45.0 & 46.7 & 4.38 & 0.64 \\
\hline
\end{tabular}

Table 1 shows the distribution of the general opinions of the teachers about "the skill rating scale" for the students of the Experimental Group. According to this, it is observed that the teachers consider some items as good, some items as very good, and some items as competent.

When Table 1 is examined, it is seen that the teachers expressed opinion about the item "Head is up for controlling other players and the area" at the level of "Competent" $\bar{X}=4.80$. It is seen that the teachers expressed opinion about the item "The transportation method (rolling, driving, passing, etc.) appropriate to the selected material is used" at the level of "Competent" $\bar{X}=4.50$.

When Table 1 is examined, it is seen that the teachers expressed opinion about the item "The ball is checked close to the body while going through the passageways "at the level of "Competent" $\bar{X}=4.41$. About the item "While moving with the ball, moves forward seeing both the ball and the obstacle "at the level of "Competent" $\bar{X}=4.38$. About the item "Is prepared for sudden stops and direction changes" at the level of "Competent" $\bar{X}=$ 4.38. About the item "Makes eye contact with the corresponding player when giving and receiving pass "at the level of "Competent" $\bar{X}=4.4 \underline{3}$. About the item "Shows his readiness, with his body position, for taking the ball "at the level of "Competent" $\bar{X}=4.56$. About the item "Follows the ball well "at the level of "Competent" $\bar{X}=$ 4.55. About the item "Takes appropriate shooting and capturing positions "at the level of "Competent" $\bar{X}=4.58$ About the item "Gives the pass in a way that the corresponding player can take it "at the level of "Competent" $\bar{X}=4.55$.

When Table 1 is examined, it is seen that the teachers expressed opinion about the item "Shows a target by hand to indicate readiness to catch the ball "at the level of "Competent" $\bar{X}=4.55$. About the item "Throws the ball at the specified target "at the level of "Competent" $\bar{X}=4.41$. About the item "Sends the ball to the desired point at an adequate speed "at the level of "Competent" $\bar{X}=4.48$. About the item "Follows the thrown ball by his eye "at the level of "Competent" $\bar{X}=4.33$. About the item "Moves quickly to go away from the defense players and is ready to pass "at the level of "Competent" $\bar{X}=4.43$. About the item "The offensive players take the position of the defensive players into account while passing "at the level of "Competent" $\bar{X}=4.40$. About the item "Makes different shots / throws at the target "at the level of "Competent" $\bar{X}=4.31$. About the item "Ebes passes at appropriate speed, taking into account the distance "at the level of "Competent" $\bar{X}=4.28$. Although it was close to very good.

When Table 1 is examined, it is seen that the teachers expressed opinion about the item "When ready to catch pass, shows by targeting his hand "at the level of "Competent" $\bar{X}=4.33$. About the item "After pass is made, immediately takes the pass-taking position "at the level of "Competent" $\bar{X}=4.35$. About the item "The offensive player shows his readiness to take pass "at the level of "Competent" $\bar{X}=4.46$. About the item "The offensive players go to empty spaces to get passes "at the level of "Competent" $\bar{X}=4.48$. About the item "The player kicks the ball towards cruciate to gain space and run inside to get the ball "at the level of "Very Good" $\bar{X}=4.06$. About the item "When making defense, first uses backward, leftward and rightward side steps "at the 
level of "Very Good" $\bar{X}=3.73$.

When Table 1 is examined, it is seen that the teachers expressed opinion about the item "Defense players give a clear signal to get the ball "at the level of "Very Good" $\bar{X}=3.95$. About the item "Passes to the free player "at the level of "Very Good" $\bar{X}=4.16$. Although it was close to "Competent", about the item "Uses side steps to mislead the defender "at the level of "Competent" $\bar{X}=4.40$. About the item "Tries to make accurate passes "at the level of "Very Good" $\bar{X}=3.96$. About the item "Passes in different directions "at the level of "Competent" $\bar{X}=4.40$. About the item "Changes the direction of the game by a single pass "at the level of "Competent" $\bar{X}=$ 4.46 .

When Table 1 is examined, it is seen that the teachers expressed opinion about the item "Moves to empty spaces to get pass "at the level of "Competent" $\bar{X}=4.45$. About the item "Runs fast at wings to get pass "at the level of "Competent" $\bar{X}=4.48$. About the item "Uses side steps to get pass in the wings "at the level of "Competent" $\bar{X}=4.41$. About the item "Uses side steps to get pass in the wings "at the level of "Very Good" $\bar{X}=4.18$. Although it was close to "Competent", about the item "Cheats to get pass in the wings "at the level of "Competent" $\bar{X}=4.33$. About the item "The player in the wings gives the pass to the most suitable player for the offense "at the level of "Competent" $\bar{X}=4.43$.

When Table 1 is examined, it is seen that the teachers expressed opinion, about the item "Controls the player on the wing while defending "at the level of "Competent" $\bar{X}=4.36$. About the item "Works in coordination while making offense and defense "at the level of "Competent" $\bar{X}=4.46$. About the item "Communicates with teammates while making offense and defense "at the level of "Competent" $\bar{X}=4.48$. About the item "Moves forward in empty space to get pass "at the level of "Competent" $\bar{X}=4.50$. About the item "Tries to make and catch appropriate pass "at the level of "Competent" $\bar{X}=4.43$. About the item "Adjusts pass distance and speed well "at the level of "Competent" $\bar{X}=4.45$.

When Table 1 is examined, it is seen that the teachers expressed opinion about the item "Trains at proper speed until skill develops "at the level of "Competent" $\bar{X}=4.32$. About the item "When starting learning the movement, makes passes and shots by sitting or standing still " at the level of "Competent" $\bar{X}=4.30$. About the item "Tries different ways of controlling the ball (by hand, with crutches, wheelchair, etc.)" at the level of "Very Good" $\bar{X}=4.18$. Although it was close to "Competent", about the item "Dedicates enough time to develop the skill "at the level of "Competent" $\bar{X}=4.38$.

Table 2. General opinions of the teachers on the "skill rating scale" for the Control Group students $p<0.05$

\begin{tabular}{|c|c|c|c|c|c|c|c|c|c|}
\hline \multirow{2}{*}{ M } & \multirow{2}{*}{ Skill rating scale } & \multirow{2}{*}{$\mathrm{N}$} & \multicolumn{5}{|c|}{ Agreement Level (\%) } & \multirow{2}{*}{$\bar{X}$} & \multirow{2}{*}{ ss } \\
\hline & & & weak & medium & good & well & Perf. & & \\
\hline 1 & Head is up for controlling other players and the area. & 60 & 0 & 0 & 0 & 15.0 & 85.0 & 4.85 & 0.36 \\
\hline 2 & $\begin{array}{l}\text { The transportation method (rolling, driving, passing, etc.) } \\
\text { appropriate to the selected material is used. }\end{array}$ & 60 & 0 & 0 & 3.3 & 33.3 & 63.4 & 4.60 & 0.55 \\
\hline 3 & $\begin{array}{l}\text { The ball is checked close to the body while going through the } \\
\text { passageways. }\end{array}$ & 60 & 0 & 0 & 3.3 & 38.4 & 58.3 & 4.55 & 0.56 \\
\hline 4 & $\begin{array}{l}\text { While moving with the ball, moves forward seeing both the } \\
\text { ball and the obstacle. }\end{array}$ & 60 & 0 & 0 & 10.0 & 43.3 & 46.7 & 4.36 & 0.66 \\
\hline 5 & Is prepared for sudden stops and direction changes. & 60 & 0 & 0 & 10.0 & 28.3 & 61.7 & 4.51 & 0.67 \\
\hline 6 & $\begin{array}{l}\text { Makes eye contact with the corresponding player when giving } \\
\text { and receiving pass. }\end{array}$ & 60 & 0 & 0 & 3.3 & 30.0 & 66.7 & 4.63 & 0.55 \\
\hline 7 & $\begin{array}{l}\text { Shows his readiness, with his body position, for taking the } \\
\text { ball. }\end{array}$ & 60 & 0 & 0 & 10.0 & 30.0 & 60.0 & 4.50 & 0.67 \\
\hline 8 & Follows the ball well. & 60 & 0 & 0 & 1.7 & 20.0 & 78.3 & 4.76 & 0.46 \\
\hline 9 & Takes appropriate shooting and capturing positions. & 60 & 0 & 0 & 5.0 & 30.0 & 65.0 & 4.60 & 0.58 \\
\hline 10 & $\begin{array}{l}\text { Gives the pass in a way that the corresponding player can take } \\
\text { it. }\end{array}$ & 60 & 0 & 0 & 8.3 & 20.0 & 71.7 & 4.63 & 0.63 \\
\hline 11 & Shows a target by hand to indicate readiness to catch the ball. & 60 & 0 & 0 & 8.3 & 31.7 & 60.0 & 4.51 & 0.65 \\
\hline 12 & Throws the ball at the specified target. & 60 & 0 & 0 & 0 & 25.0 & 75.0 & 4.75 & 0.43 \\
\hline 13 & Sends the ball to the desired point at an adequate speed. & 60 & 0 & 0 & 1.7 & 43.3 & 55.0 & 4.53 & 0.53 \\
\hline 14 & Follows the thrown ball by his eye. & 60 & 0 & 0 & 0 & 33.3 & 66.7 & 4.66 & 0.47 \\
\hline 15 & $\begin{array}{l}\text { Moves quickly to go away from the defense players and is } \\
\text { ready to pass. }\end{array}$ & 60 & 0 & 0 & 10.0 & 48.3 & 41.7 & 4.31 & 0.65 \\
\hline 16 & $\begin{array}{l}\text { The offensive players take the position of the defensive } \\
\text { players into account while passing. }\end{array}$ & 60 & 0 & 0 & 11.7 & 53.3 & 35.0 & 4.23 & 0.64 \\
\hline
\end{tabular}




\begin{tabular}{|c|c|c|c|c|c|c|c|c|c|}
\hline 17 & Makes different shots / throws at the target. & 60 & 0 & 0 & 5.0 & 40.0 & 55.0 & 4.50 & 0.59 \\
\hline 18 & $\begin{array}{l}\text { Ebes passes at appropriate speed, taking into account the } \\
\text { distance. }\end{array}$ & 60 & 0 & 0 & 3.3 & 43.3 & 53.4 & 4.50 & 0.56 \\
\hline 19 & When ready to catch pass, shows by targeting his hand. & 60 & 0 & 0 & 8.3 & 53.4 & 38.3 & 4.30 & 0.61 \\
\hline 20 & $\begin{array}{l}\text { After pass is made, immediately takes the pass-taking } \\
\text { position. }\end{array}$ & 60 & 0 & 0 & 11.7 & 45.0 & 43.3 & 4.31 & 0.67 \\
\hline 21 & The offensive player shows his readiness to take pass. & 60 & 0 & 0 & 1.7 & 40.0 & 58.3 & 4.56 & 0.53 \\
\hline 22 & The offensive players go to empty spaces to get passes. & 60 & 0 & 0 & 5.0 & 41.7 & 53.3 & 4.48 & 0.59 \\
\hline 23 & $\begin{array}{l}\text { The player kicks the ball towards cruciate to gain space and } \\
\text { run inside to get the ball. }\end{array}$ & 60 & 0 & 0 & 20.0 & 43.3 & 36.7 & 4.16 & 0.74 \\
\hline 24 & $\begin{array}{l}\text { When making defense, first uses backward, leftward and } \\
\text { rightward side steps. }\end{array}$ & 60 & 0 & 0 & 41.7 & 48.3 & 10.0 & 3.68 & 0.65 \\
\hline 25 & Defense players give a clear signal to get the ball. & 60 & 0 & 0 & 35.0 & 31.7 & 33.3 & 3.98 & 0.83 \\
\hline 26 & Passes to the free player. & 60 & 0 & 0 & 25.0 & 40.0 & 35.0 & 4.10 & 0.77 \\
\hline 27 & Uses side steps to mislead the defender. & 60 & 0 & 0 & 10.2 & 40.6 & 49.2 & 4.38 & 0.66 \\
\hline 28 & Tries to make accurate passes. & 60 & 0 & 0 & 33.3 & 28.3 & 38.4 & 4.05 & 0.85 \\
\hline 29 & Passes in different directions. & 60 & 0 & 0 & 5.0 & 30.0 & 65.0 & 4.60 & 0.58 \\
\hline 30 & Changes the direction of the game by a single pass. & 60 & 0 & 0 & 3.3 & 33.4 & 63.3 & 4.60 & 0.55 \\
\hline 31 & Moves to empty spaces to get pass. & 60 & 0 & 0 & 5.0 & 40.0 & 55.0 & 4.50 & 0.59 \\
\hline 32 & Runs fast at wings to get pass. & 60 & 0 & 0 & 1.7 & 38.3 & 60.0 & 4.58 & 0.53 \\
\hline 33 & Uses side steps to get pass in the wings. & 60 & 0 & 0 & 1.7 & 50.0 & 48.3 & 4.46 & 0.53 \\
\hline 34 & Uses side steps to get pass in the wings. & 60 & 0 & 0 & 23.3 & 40.0 & 36.7 & 4.13 & 0.76 \\
\hline 35 & Cheats to get pass in the wings. & 60 & 0 & 0 & 8.3 & 46.7 & 45.0 & 4.36 & 0.63 \\
\hline 36 & $\begin{array}{l}\text { The player in the wings gives the pass to the most suitable } \\
\text { player for the offense. }\end{array}$ & 60 & 0 & 0 & 15.0 & 36.7 & 48.3 & 4.33 & 0.72 \\
\hline 37 & Controls the player on the wing while defending. & 60 & 0 & 0 & 11.7 & 38.3 & 50.0 & 4.38 & 0.69 \\
\hline 38 & Works in coordination while making offense and defense. & 60 & 0 & 0 & 8.5 & 39.0 & 52.5 & 4.44 & 0.65 \\
\hline 39 & $\begin{array}{l}\text { Communicates with teammates while making offense and } \\
\text { defense. }\end{array}$ & 60 & 0 & 0 & 1.7 & 48.3 & 50.0 & 4.48 & 0.53 \\
\hline 40 & Moves forward in empty space to get pass. & 60 & 0 & 0 & 1.7 & 35.0 & 63.3 & 4.61 & 0.52 \\
\hline 41 & Tries to make and catch appropriate pass. & 60 & 0 & 0 & 1.7 & 33.3 & 65.0 & 4.63 & 0.51 \\
\hline 42 & Adjusts pass distance and speed well. & 60 & 0 & 0 & 1.7 & 31.7 & 66.6 & 4.65 & 0.51 \\
\hline 43 & Trains at proper speed until skill develops. & 60 & 0 & 0 & 5.0 & 43.3 & 51.7 & 4.46 & 0.59 \\
\hline 44 & $\begin{array}{l}\text { When starting learning the movement, makes passes and shots } \\
\text { by sitting or standing still. }\end{array}$ & 60 & 0 & 0 & 13.3 & 48.3 & 38.4 & 4.25 & 0.67 \\
\hline 45 & $\begin{array}{l}\text { Tries different ways of controlling the ball (by hand, with } \\
\text { crutches, wheelchair, etc.). }\end{array}$ & 60 & 0 & 0 & 20.0 & 48.3 & 31.7 & 4.11 & 0.71 \\
\hline 46 & Dedicates enough time to develop the skill. & 60 & 0 & 0 & 13.3 & 28.3 & 58.4 & 4.45 & 0.73 \\
\hline
\end{tabular}

Table 2 shows the distribution of the general opinions of the teachers about "the skill rating scale" for the students of the Control Group. According to this, it is observed that those participating in the research consider some opinion items of the students as good, some items as very good, and some items as competent.

When Table 2 is examined, it is seen that the teachers expressed opinion about the item "Head is up for controlling other players and the area" at the level of "Competent" $\bar{X}=4.85$.

When Table 2 is examined, it is seen that the teachers expressed opinion about the item "The transportation method (rolling, driving, passing, etc.) appropriate to the selected material is used" at the level of "Competent" $\bar{X}=4.60$.

When Table 2 is examined, it is seen that the teachers expressed opinion about the item "The ball is checked close to the body while going through the passageways "at the level of "Competent" $\bar{X}=4.55$. About the item "While moving with the ball, moves forward seeing both the ball and the obstacle "at the level of "Competent" $\bar{X}=4.36$. About the item "Is prepared for sudden stops and direction changes" at the level of "Competent" $\bar{X}=$ 4.51. About the item "Makes eye contact with the corresponding player when giving and receiving pass "at the level of "Competent" $\bar{X}=4.63$. About the item "Shows his readiness, with his body position, for taking the ball "at the level of "Competent" $\bar{X}=4.50$. About the item "Follows the ball well "at the level of "Competent" $\bar{X}$ $=4.76$. About the item "Takes appropriate shooting and capturing positions "at the level of "Competent" $\bar{X}=$ 4.60. About the item "Gives the pass in a way that the corresponding player can take it "at the level of "Competent" $\bar{X}=4.63$.

When Table 2 is examined, it is seen that the teachers expressed opinion about the item "Shows a target by hand 
to indicate readiness to catch the ball "at the level of "Competent" $\bar{X}=4.51$. About the item "Throws the ball at the specified target "at the level of "Competent" $\bar{X}=4.75$. About the item "Sends the ball to the desired point at an adequate speed "at the level of "Competent" $\bar{X}=4.53$. About the item "Follows the thrown ball by his eye "at the level of "Competent" $\bar{X}=4.66$. About the item "Moves quickly to go away from the defense players and is ready to pass "at the level of "Competent" $\bar{X}=4.31$. About the item "The offensive players take the position of the defensive players into account while passing "at the level of "Competent" $\bar{X}=4.23$. Although it was close to "Very good", about the item "Makes different shots / throws at the target "at the level of "Competent" $\bar{X}=4.50$. About the item "Ebes passes at appropriate speed, taking into account the distance "at the level of "Competent" $\bar{X}=4.40$. Although it was close to "Very Good".

When Table 2 is examined, it is seen that the teachers expressed opinion about the item "When ready to catch pass, shows by targeting his hand "at the level of "Competent" $\bar{X}=4.30$. About the item "After pass is made, immediately takes the pass-taking position "at the level of "Competent" $\bar{X}=4.31$. About the item "The offensive player shows his readiness to take pass "at the level of "Competent" $\bar{X}=4.56$. About the item "The offensive players go to empty spaces to get passes "at the level of "Competent" $\bar{X}=4.48$. About the item "The player kicks the ball towards cruciate to gain space and run inside to get the ball "at the level of "Very Good" $\bar{X}=4.16$. About the item "When making defense, first uses backward, leftward and rightward side steps "at the level of "Very Good" $\bar{X}=3.68$.

When Table 2 is examined, it is seen that the teachers expressed opinion about the item "Defense players give a clear signal to get the ball "at the level of "Very Good" $\bar{X}=3.98$. About the item "Passes to the free player "at the level of "Very Good" $\bar{X}=4.10$. Although it was close to "Competent", about the item "Uses side steps to mislead the defender "at the level of "Competent" $\bar{X}=4.38$. About the item "Tries to make accurate passes "at the level of "Very Good" $\bar{X}=4.05$. About the item "Passes in different directions "at the level of "Competent" $\bar{X}=4.60$. About the item "Changes the direction of the game by a single pass "at the level of "Competent" $\bar{X}=$ 4.60. About

When Table 2 is examined, it is seen that the teachers expressed opinion about the item "Moves to empty spaces to get pass "at the level of "Competent" $\bar{X}=4.50$. About the item "Runs fast at wings to get pass "at the level of "Competent" $\bar{X}=4.48$. About the item "Uses side steps to get pass in the wings "at the level of "Competent" $\bar{X}=4.46$. About the item "Uses side steps to get pass in the wings "at the level of "Very Good" $\bar{X}=4.13$. About although it was close to "Competent", about the item "Cheats to get pass in the wings "at the level of "Competent" $\bar{X}=4.36$. About the item "The player in the wings gives the pass to the most suitable player for the offense "at the level of "Competent" $\bar{X}=4.33$. About

When Table 2 is examined, it is seen that the teachers expressed opinion, about the item "Controls the player on the wing while defending "at the level of "Competent" $\bar{X}=4.38$. About the item "Works in coordination while making offense and defense "at the level of "Competent" $\bar{X}=4.44$. About the item "Communicates with teammates while making offense and defense "at the level of "Competent" $\bar{X}=4.48$. About the item "Moves forward in empty space to get pass "at the level of "Competent" $\bar{X}=4.61$. About the item "Tries to make and catch appropriate pass "at the level of "Competent" $\bar{X}=4.63$. About the item "Adjusts pass distance and speed well "at the level of "Competent" $\bar{X}=4.65$.

When Table 2 is examined, it is seen that the teachers expressed opinion about the item "Trains at proper speed until skill develops "at the level of "Competent" $\bar{X}=4.46$. About the item "When starting learning the movement, makes passes and shots by sitting or standing still " at the level of "Competent" $\bar{X}=4.25$. Although it was close to "Very Good", about the item "Tries different ways of controlling the ball (by hand, with crutches, wheelchair, etc.)" at the level of "Very Good" $\bar{X}=4.11$. About although it was close to "Competent", about the item "Dedicates enough time to develop the skill "at the level of "Competent" $\bar{X}=4.45$.

Table 3. Opinions of the teachers, participating in the research, about skill observation form, by group variable

\begin{tabular}{|c|c|c|c|c|c|c|}
\hline \multirow{2}{*}{ Item } & \multirow{2}{*}{ Group } & \multicolumn{3}{|c|}{ Agreement Levels } & \multirow[b]{2}{*}{$\chi^{2}$} & \multirow[b]{2}{*}{$\mathrm{p}$} \\
\hline & & 3 & 4 & 5 & & \\
\hline \multirow[t]{2}{*}{10} & Control & 5 & 12 & 43 & \multirow{2}{*}{7,711} & \multirow{2}{*}{$0,021^{*}$} \\
\hline & Experimental & 1 & 24 & 34 & & \\
\hline \multirow[t]{2}{*}{12} & Control & 0 & 15 & 45 & \multirow{2}{*}{11,413} & \multirow{2}{*}{$0,003^{*}$} \\
\hline & Experimental & 3 & 29 & 28 & & \\
\hline
\end{tabular}


When Table 3, which studies the opinions about the skill observation form by the group variable of the teachers participating in the research, is examined, it was found that while only in $10^{\text {th }}$ and $12^{\text {th }}$ items there is significant difference $(\mathrm{p}<.05)$, in other items there is no statistically significant difference.

When Table 3 is examined, it was determined that there is significant difference in the opinions of the teachers by the group variable about the opinion "Gives the pass in a way that the corresponding player can take it" $(\chi 2=$ $7.711 ; \mathrm{p}<.05)$. It is observed that the teachers agree with the opinion of "Gives the pass in a way that the corresponding player can take it" more in the test for control group students. It can be said that the reason that the teachers agree with this opinion less in the test for the experimental group is that they thought that the students had learned this skill with its rules and in a better way.

Again when Table 3 is examined, it was determined that there is significant difference in the opinions of the teachers by the group variable about the opinion "Throws the ball at the specified target" $\left(\chi^{2}=11.413 ; \mathrm{p}<.05\right)$. It is observed that the teachers agree with the opinion of "Throws the ball at the specified target" more in the test for control group students. As we stated above, it can be said that the reason that the teachers agree with this opinion less in the test for the experimental group is that they thought that the students had learned this skill with its rules and in a better way.

Table 4. Teachers' opinions about PAC applied in $7^{\text {th }}$ grade

\begin{tabular}{|c|c|c|}
\hline Questions & Teacher & Teacher Statements \\
\hline $\begin{array}{l}\text { Are the applied cards appropriate for } \\
\text { the level of the students? }\end{array}$ & $\mathrm{T} 1-\mathrm{T} 2$ & $\begin{array}{l}\text { The cards are appropriate for the level of the students. The students did not use this } \\
\text { method in physical education courses, while they were using it in courses like Turkish, } \\
\text { Mathematics and Science. Students needed guidance when they were using the cards. }\end{array}$ \\
\hline $\begin{array}{l}\text { Did the students easily understand the } \\
\text { cards and the activities? }\end{array}$ & $\mathrm{T} 1-\mathrm{T} 2$ & $\begin{array}{l}\text { Since the students were familiar with the application in other classes, they did not have } \\
\text { major problems in understanding it, but in some cases, they needed guidance. }\end{array}$ \\
\hline $\begin{array}{l}\text { Was the participation of the students } \\
\text { ensured? }\end{array}$ & $\mathrm{T} 1$ & $\begin{array}{l}\text { The crowdedness of the classrooms did not prevent students from attending the class. } \\
\text { All students' participation was ensured. }\end{array}$ \\
\hline $\begin{array}{l}\text { Did classroom control was ensured } \\
\text { easily? }\end{array}$ & $\mathrm{T} 1$ & $\begin{array}{l}\text { Although due to participation of all of the students in the class minor problems in class } \\
\text { control were experienced, generally, the control was achieved. }\end{array}$ \\
\hline Did the students have fun? & $\mathrm{T} 2$ & $\begin{array}{l}\text { Because our education system is examination-oriented, students look forward to the } \\
\text { physical education classes. The application of PAC in the class both brought variety to } \\
\text { the class and made the students have fun. }\end{array}$ \\
\hline $\begin{array}{l}\text { Did the students act individually or in } \\
\text { groups while the cards were taught? }\end{array}$ & $\mathrm{T} 1$ & $\begin{array}{l}\text { Peer education and PAC are an effective method in students' active participation in } \\
\text { class. Since the students willingly participated in classes, they acted both individually } \\
\text { and in groups. }\end{array}$ \\
\hline $\begin{array}{l}\text { Did the students treat their friends } \\
\text { respectfully during the performance of } \\
\text { the activities? }\end{array}$ & $\mathrm{T} 1-\mathrm{T} 2$ & $\begin{array}{l}\text { The students treated each other respectfully by participating in events both individually } \\
\text { and in groups. }\end{array}$ \\
\hline
\end{tabular}

\section{Discussion}

Many physical educator teachers are using groupwork as a teaching strategy in their lessons. It provides to learn more about effective groupwork strategies. There are many research studies supporting the idea that collaborative methods have a positive effect on student achievement in almost any discipline (Bennett, 2015; Rezaei, 2015). In result of our research, it has been determined that the PAC has increased the physical activity levels of the students. Whereas an increase has been observed in the level of skill teaching of the students, a considerable decrease has been observed in their level of free game playing. Through the PAC the teachers have encouraged the students to exercise, guided and observed them. The teachers in the control group have turned to managing the students and lecturing skills instead of observing.

Usluoğlu \& Mirzeoğlu (2017), informed that most of the students stated that they liked the lessons, enjoyed having lessons with cards and improved their movement skills, and also having lesson with cards increased their participation. When the views of physical education teachers of students were analyzed, they stated that the cards increased the participation level of the students.

Hürmeriç (2003), examined the students' physical activity levels, their course contents, and teacher behaviors, and the relationship between these elements by comparing private and public schools - used a sample group consisting of 19 teachers working at private and public schools in the province of Ankara. Within the scope of the research, he observed the 144-person group, consisting of $7^{\text {th }}$ and $8^{\text {th }}$ grade students at elementary school, through the SOFIT observation tool for 36 hours in total. In result of the study, he found that the use of the PAC 
increased the level of physical activity of the students. The students learned skills when they were ready to learn. The findings we obtained in our research overlap with these findings.

Hürmeriç et al. (2002), measured the physical activity levels of secondary school students (128 students), as sample group, were observed through the SOFIT program, and it was determined that the students spent $9,07 \%$ of the class time by sitting, $54,85 \%$ by standing, $26,7 \%$ by walking and $9,89 \%$ by running. It was determined, in result of the research, that the students spent $35.97 \%$ of the class time by walking and running. The findings in our research are similar to the study by Hürmeriç and his colleagues.

\section{References}

Bennett, T. (2015). Group Work for the Good; Unpacking the Research behind One Popular Classroom Strategy. American Educator, 1, 32-43. https://doi.org/10.1177/1469787415589627

Harris, J., Cale, L., \& Musson H. (2007). Evaluation of the impacts of the TOP programs on teaching and learning in primary schools in England. Loughborough University, England.

Hürmeriç, I. (2003). Evaluation of Health-Related Physical Activity Levels of Students, Course Content, and Teacher Behaviors in Primary School Physical Education. Master's Thesis. Ankara: Middle East Technical University, Institute of Social Sciences.

Hürmeriç, I., Kirazc1, S., Cicek, Ş., \& İnce, M. L. (2002). Physical Activity Levels of Students and Course Contents in Primary School Second-Level Physical Education Courses. $7^{\text {th }}$ International Sports Sciences Congress, Seminar Book.

McKenzie, T. L., Catellier, D. J., Conway, T., Lytle, L. A., Griese, M., Webber, L. A., Pratt, C. A., \& Elder J. P. (2006). Girls' activity levels and lesson contexts in middle school PE: TAAG baseline. Medicine and Science in Sports and Exercise, 38(7), 1229-1235. https://doi.org/10.1249/01.mss.0000227307.34149.f3

National Education Ministry. (2012). 12 Years Compulsory Education, Questions-Answers.

Rezaei, A. R. (2015). Frequent collaborative quiz taking and conceptual learning. Active Learning in Higher Education, 16(3), 187-196. https://doi.org/10.1177/1469787415589627

Roberts, D., Leach, R., Harries, J., Phillips, R. W., Newton, H. R., \& Jones, S. (1998). TOP play and BT TOP sport in the North West. The Bulletin of Physical Education, 34(2), 134-145.

Sabin, V. (1997). Integration of TOP Play/ BT TOP sport activities into a progressive primary school games program. NWCPEA Bulletin, Edition 8.

Simons-Morton, B. G., Taylor, W. C., Snider, S. A., Huang, I. W., \& Fulton, J. E. (1994). Observed levels of elementary and middle schoolchildren's physical activity during physical education classes. Preventive Medicine, 23, 437-441. https://doi.org/10.1006/pmed.1994.1059

Torphe, S. (2013). International Inspiration Project, Lecture Notes on Presentation of TOPS Cards, Ankara.

Usluoğlu, Z., \& Mirzeoğlu, A. (2017). Views towards Physical Activity Cards and the Effects of Cards on Students' Attitudes. Pamukkale Spor Bilimleri Dergisi, 8(2), 1-14.

\section{Copyrights}

Copyright for this article is retained by the author, with first publication rights granted to the journal.

This is an open-access article distributed under the terms and conditions of the Creative Commons Attribution license (http://creativecommons.org/licenses/by/4.0/). 